\title{
THE EARLY TREATMENT OF THE HEAD-INJURED PATIENT
}

\author{
JAN MCGUIRE, M.C.S.P. \\ Semior: Phusiolierapist in cliarge of Newro-Surgical Unit, \\ Croute Schan Hospinal, Cape Town.
}

The most importint consideration where there is some degice of unconsciousness in a patient with a heatinjury, is to KEEP THE AIRWAY FlREE. The brain receives neirly $20^{\circ}$, of the total cardiac output of the body. and if the airway is obstructed, the increased $\mathrm{CO}$ increases the blood volume within the skull due to vasodilation. This hat the elfect of raising indracranial pressule. with secondary compression and death of many brain cells and resultant permanent brain damage. This may occur very rapidy. even in a period of only few hours. Where there is ccrebral ocdema or any other ciduse of incriand pressure within the cranium. such as a subdural haematoma. or tumour, the skull itselt camnot. of coulse. expand, so that the pressure is exerted downwarls and centrally towards the tentorial notch and brainstem. Here, where there are thousands of fibres converging on a very small area, a great deal of damage can be done, giving rise to pressure on one or more cranial nerves, varying degrces of spasticity, inemiplegia and so on. The recticular formation can also be damaged, with resultant further depression of the conscious level.

\section{Degrees of Consciousness:}

1. The patient may be drowsy. but can casily bo roused and can give a good account in terms of name, place, time, etc.

2. Disorientilted. but still able to tell the stall his name and address.

3. Only a grunt. but at least an attempt at a verbal response! When there is no longer any verbal response, a painful stimulus can be produced by rubbing the patient's sternum firmly with the knuckle. This may then give lise to the following reactions:-

4. The patient will atlempt to push away the hand with both of his in a purposeful manner. It can also be noted at this juncture whether there is a completc ol partially paralysed arm.

5. The patient extends his legs. flexes his elbows, and clenches his fists. This is known as the decorticate posture. probably indicuting that the cortex is not responding. only the brain stem and diencephalon. (See illustration .No. 1.)

6. The patient exicnds and internally rotates his arms and extends his legs. This is the decerebrate posture. probably indicating that the brain stem alone controls the patient's reactions. and the outlook is more scrious, (Sce illustration No. 2.)

7. The patient is in a comat, with complete lack of responsc to any stimulus, the limbs are flaccid and the outlook is grave.

Patients, if adequately nursed, can remain for months. or even years. without regaining consciousness in any of the states described, in 5, 6, and 7 .

\section{Observations:}

Because the patient's condition can alter so rapidly. it is extremely important that during daily treatment accurate observations are made by the physiotherapist of the patient's reactions, and any deterioration im- medialcly reporide to the doctor. There are two condilions in parlicular that call for urgent action:-

Further detcrioution of consciousness, indicating or increasing intracranial pressule, with cercbral hill and brain stem compression

2. A slaggishly reating or completely fixed pupil to light. showing that the 3 id cranial nave foculomotor) has itso become involved at the iencoria notch.

Degrees of Paralysis:

1. Monoparesis. one limb only involved, ustatly th arm. If the face and leg on that side are not part. lysed one must suspect a locil injury such as. brachial plexus lesion.

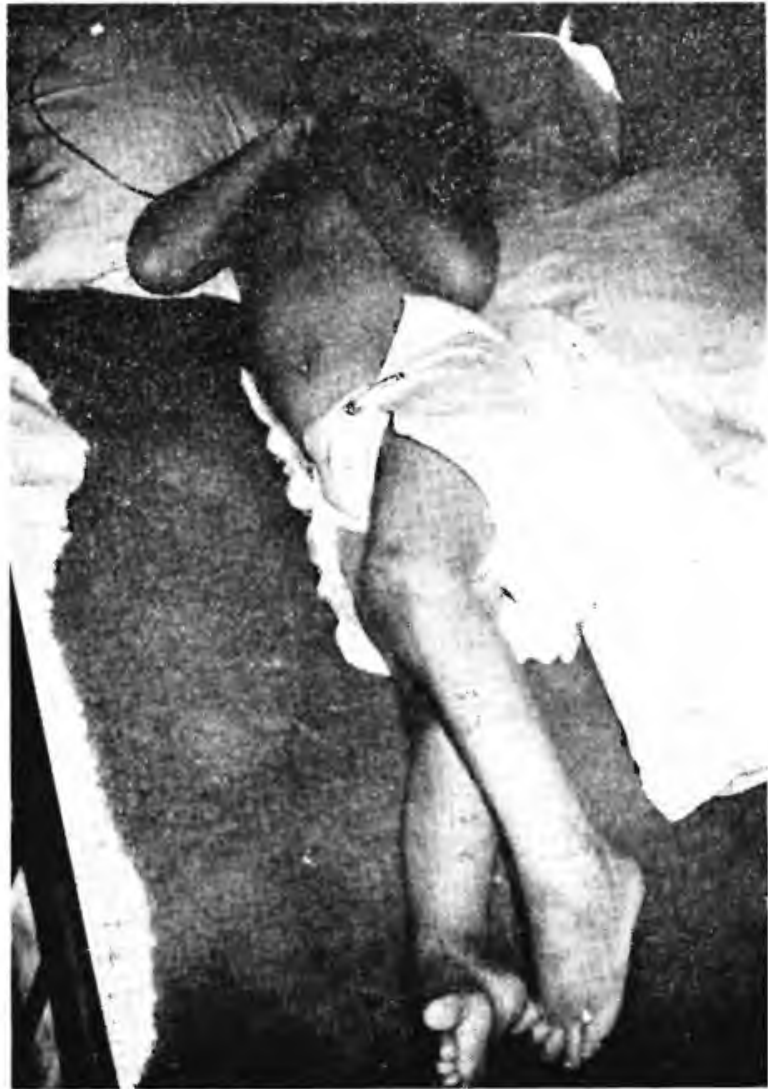

Fig. 1. The typical decorticate position of a child with a severe brain-stem injury, after many months in hospital.

2. Hemiparesis or hemiplegia, depending on the degree of the paralysis. It has been noticed that although a patient may have a left subdural haematoma, it does not necessarily follow that he will 


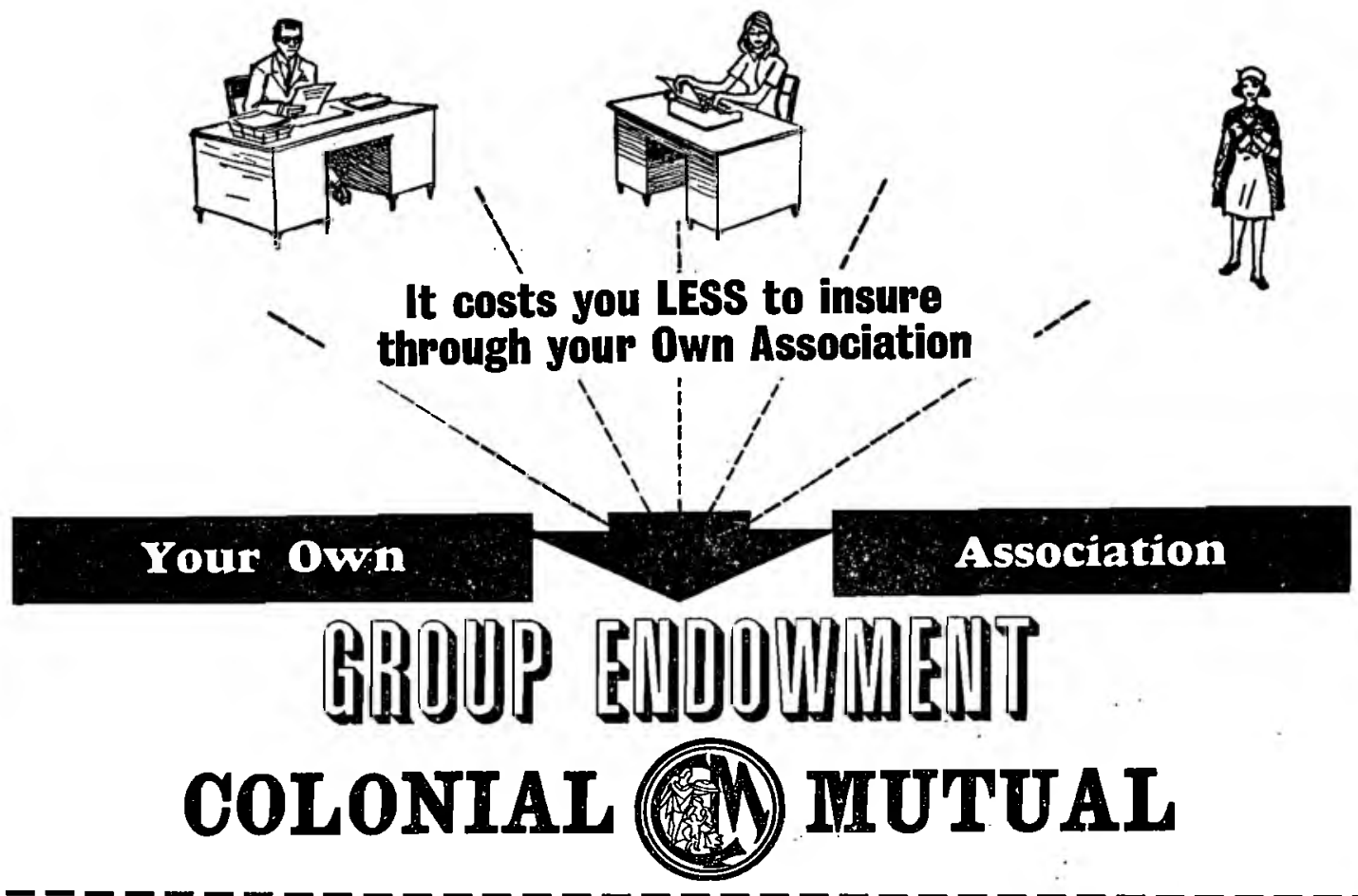

To the Trustees, S.A. SOCIETY OF PHYSIOTHERAPISTS, Group Endow ment Fund, P.O. Box 1194, Johannesburg.

Without obligation, please tell me how I can obtain MAXIMUM protection at MINIMUM cost-plus valuable disability benefits-by insuring through my own Association Group Endowment Fund.

NAME

ADDRESS
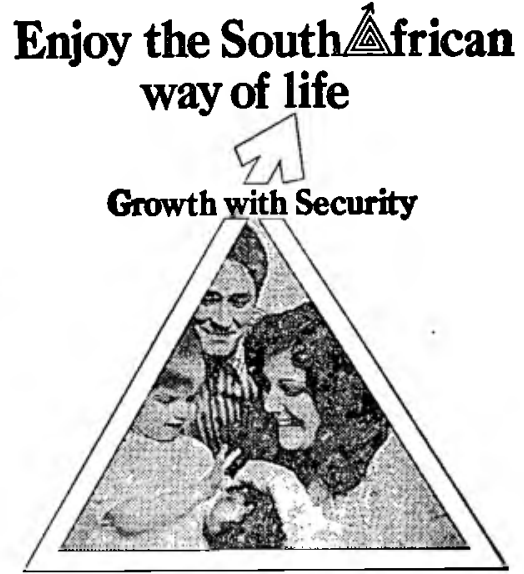

Save and $\rightarrow$ invest

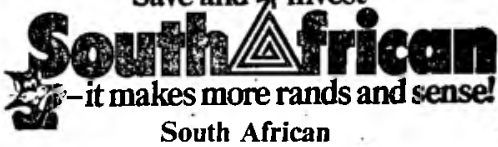

Permanent Building Society

\section{A. C. MILLER \& CO. ORTHOPAEDIC MECHANICIANS}

Technicians registered with S.A. Medical and Dental Council specialising in the following: ORTHOPAEDIC APPLIANCES, SURGICAL CORSETS, CERVICAL COLLARS, CHILDREN'S SHOES AND BOOTS, ARTIFICIAL LIMBS, LATEST IN PLASTIC MODIFICATION. HIRING AND SELLING OF HOSPITAL EQUIPMENT AND SICK ROOM REQUISITES, e.g. WHEEL CHAIRS, COMMODES, HOSPITAL BEDS, WALKING AIDS, TRACTION APPARATUS, etc.

๑

Telephone P.O. Box 3412 23-2496 


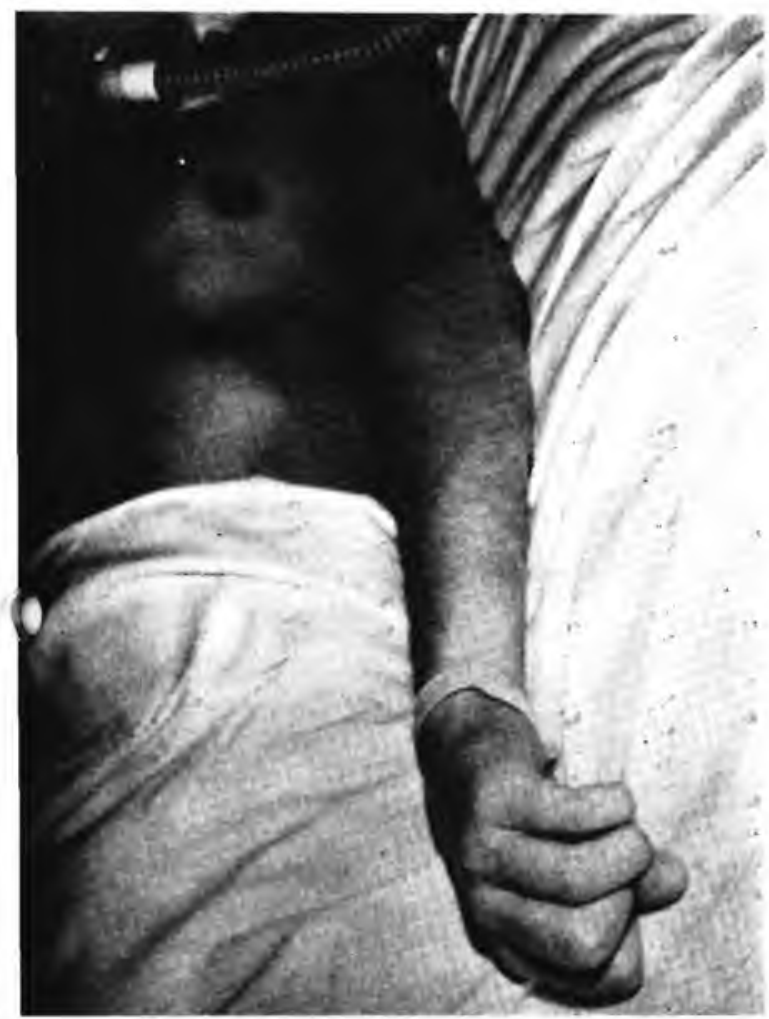

Fig. 2. The typical internally rotated arm of a decerebrate patient. Any external stimulus will produce extreme extensor spasin in the limb.

always have a hemiplegia on his right side, as would occur with a case of CVA. In one out of five cases the paralysis is on the same side as the compressing surface haematoma. This is because the expanding lesion on the onc side will cause at brain shift to the opposite side so that the opposite cerebral peduncle will be compressed by the edge of the tentorium cerebelli, thus paralysing fibres which will decussate to the limbs on the side of the expanding lesion.

3. A, Flacid hemiplegia.

B, Spastic hemiplegia.

4. Paraplegia - Paralysis of both legs usually seen with spinal injuries but rarely also with certain intraccrebral lesions at the vertex.

5. Teraplegia - Paralysis of all four limbs. usually indicating high cervical spinal cord injury.

\section{Tipping:}

Any unconscious patient who has secretions in his chest, has the foot of the bct raiscd seven inches to assure continuous slight drainage. This height does not constitute postural drainage for treatment of the chest; the bed can be further elevated if that is required. It does, however, ensure that the secretions from the trachea flow fleely into the mouth. When the patient is lying in a hospital bed with a sagging mattress, the secretions tend to remain in the chest and produce respiratory complications very easily. It might be thought that the oedema within the head would increase by continuous tipping, but an obstructed airway will produce a much greater increase in intracranial pressure. In cases of assault, there is often external oedema and here one hesitates to tip except for the duration of a specific chest treatment. It is also unwise to tip obese patients due to the increased effort required to move the hoavy abdominal contents pressing upwards against the diaphragm.

\section{The importance of suctioning:}

Where there has been a brain-stem lesion, or very low level of consciousness, the cough reflex is somctimes depressed or absent. In addition, no unconscious immobile patient coughs without external stimulation. Hence it is absolutely essential to assess whether the patient has any sccretions by stimulating him to cough. Passing a moistened suction catheter gently down the patient's pharynx via his nose, usually suffices. If the cough is non-productive, if he is being turned at twohourly intervals, and no anacsthetic has been given, the chest should remain clear. A quick daily check is, however, neccsesary and a routine chest treatment carried out after any operation. Do not suction through the nose if there has been much bleeding from it, or where cerebrospinal fluid is leaking from the nose.

\section{Turning:}

The patient is turned from side to side by the nurses every two hours. A pillow is placed at his back to keep him so, and where there is any paralysis of the lower limbs a pillow is placed between the knees. If he is very restless. he may be found lying on his back. but this is not a good position for the unconscious patient as the jaw and tongue will drop back and block his airway. Rather use a bolster under one side of the mattress, and pad the cotsides with pillows so that he remains on his side. preferably slightly prone. Light handcuffs made of foam rubber and Velcro frequently have to be used in this type of case to prevent the pulling out of Ryles tubing, drips. etc.

\section{Physiotherapy Treatment:}

Most head-injuries fall into one of three main categories:

(a) The minor injury, such as the semi-conscious patient with a depressed fracture or haematoma, who recovers full consciousness within a few hours or days;

(b) The patient who remains unconscious for several weeks. has had a tracheostomy performed, and has probably a mild degree of spastic hemiplegia;

(c) The severe brain-stem lesion, the patient with a tracheostomy, and decorticate or decerebrate reactions and considerable generalised spasm.

All the above may occur in at patient with multiple injuries such as limb fraclures. haemathorax. or visceral injury, in which case the treatment would have to bc adjusted accordingly. The following suggested licatments are for the head-injury only.

\section{THE MINOR INJURY:}

(a) Chest routine as considered earlier.

(b) Check all limbs to see it there is any weakness. A painful stimulus on the muscles will produce irritable movements and make obvious any hemiplegia. Passive movements are then given for it. with daily verbal and active attempts to stimulate the patient to move the limbs. Recovery with this type of case is usually rapid and uneventful. 


\section{THE MORE SEVERE INJURY:}

The basic treatment is the same, but more attention must be given to keeping the chest clear. The patient may have no active movement except for extensor spasm in one arm and leg at the slightest external stimulus. As the cerebral lesions and his general condition improve, spontaneous movements of his normal limbs will be the first to return.

To do passive movements on the affected side, the extensor spasm in the leg can usually be relaxed by slightly abducting and internally rotating the hip, then firmly flexing the toes and bending the kneo at the same time. If the spasm still persists, do not force the movement, but shake and roll the limb before repeating the procedure. Tne ankle can best be dorsi-flexed whilsi the knee is bent. Holding the foot firmly in that position, slowly straighten the knee to obtain the fullest stretch. The spasm of the Achilles tendon, which can be very severe at times, improves rapidly as consciousness is regained, and no splinting or sandbags have been found necessary. Passive movements done several times a day seem to produce the best results. Once tine patient is standing, the spasm relaxes and the weight of the body stretches the last few degrees of the range.

The extensor spasm in the arm can, after a week or so, evolve into a flexor spasm of the elbow, which may prove difficult to cope with. The shoulder should be mobilised gently because of the danger of a firozen shoulder due to capsular tearing. Abduct and externally rotate the arm and while elevating it, slightly shake and gradually stretch it at the elbow. Where resistence is felt, bring the arm down again and repeat the whole process until you have obtained as great a range of movement as possible without forcing. Finally, mobilise wrist and fingers in the elevated position.

Providing the patient's temperature and BP is normal, and he seems to be improving in his reactions, he can gradually be sat up, first in bed, and within a day or two, out in a chair, with head and arms firmly supported. If circumstances permit, he can be put in a cold bath daily by the nursing staff, even with the tracheostomy tube still in situ. The stimulation produced by cold water and sitting up, improves the conscious state rapidly. At this stage, a response to command may be forthcoming. At the request: "Squeeze my hand", one may feel a slight grip, which indicates that although the patient may not seem awake or registering anything going on about him, and is not attempting to vocalise. re can at least hear and comprehend.

Now the rehabilitation programme can commence. The patient may be confused and may only react to a few commands at first, but with constant stimulus of movement and the physiotherapist's voice, improvement can be rapid. Mat routine should be started. with particular attention to head control and balance. To begin with one has to put the patient into the desired positions, e.g. with the patient in supine, lift and turn his head to encourage him to roll; raise his hips in bridging. Roll him into prone-lying, remembering that if he still has a tracheostomy, a pillow must be put under his chest. Place his elbows under his shoulders with his hands forwards, and encourage him to lift his head. Brisk stimulation of the trapezius muscle and assistance in raising the head may well produce co-operation from the patient even if he cannot hold his head up for long. This might suffice for the first mat treatment as he is often only semi-conscious at this stage. Next day try sitting the patient up from side-lying, leaning on one elbow or the outstretched arm, or putting him into four point kneeling. A second person's help may be needed here, to allow one to concentrate on a possible hemiplegia arm. Encourage the triceps by skin stimula- tion and give further constant reminders to the patient to keep his head up. Put him into long sitting, leaning back on his hands and you may find him pushing himself forward along the mat. If he resists long-sitting, le! him sit cross-legged, as balance is easier in that position. All the time one tries to make the patient use his own balancing mechanisms and to regain some of his postural body-righting reflexes. Even a semi-conscious patient with minimal paresis, when put into four point kneeling has been known to attempt to get him. self to his feet without any commands being given, and attempt to walk with the assistance of the physiotherapist. One should not have any fixed ideas on treatment,

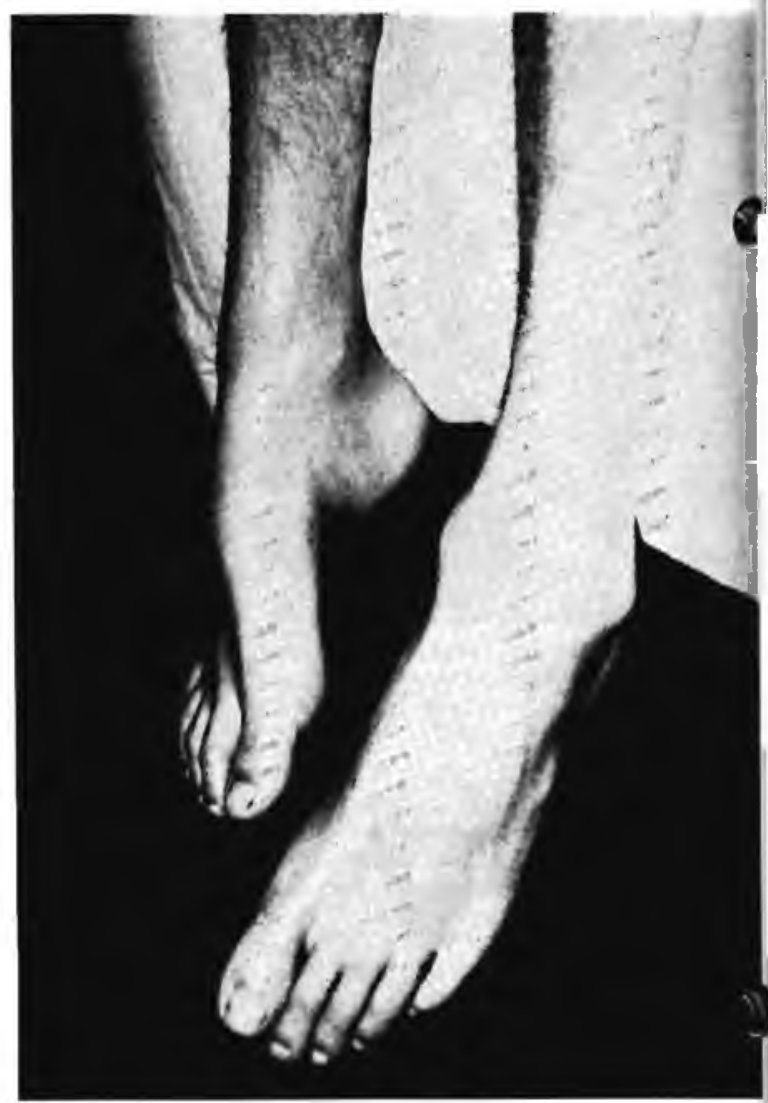

Fig. 3. The feet of a patient with a long-term brainstem injury.

and one has to "play it by ear" a good deal of the time, as no two cases are the same. Only when the patient is fully conscious, can one begin any strengthening exercises. It is then also that one can encourage attempts to speak, and give him pen and paper to see if he can write his name, and so on. At this stage, the help of the speech therapist can be enlisted.

\section{SEVERE BRAIN-STEM INJURY:}

The basic treatment is as before, keeping the chest clear, and mobilising the patient as much as possible. Many brain-stem injured, however, have gross spasticity and maintain it for many months, with no spontaneous movement. One can only attempt to keep the patient mobile in the hope that he will eventually regain consciousness, with minimal fixed contractures. It has been 
found that whether the patient is in side-lying or supine, a sandbag placed so that the head is flexed forward a little, can sometimes relieve the spasm. When he has been turned into prone-lying, leave him for a short time with his arms up above his head. Where there is a very spastic hip or knee, bring the patient in supine to the edge of the bed and in addition to a shaking of the leg and abduction of the hip, bend the knee over the edge of the bed as the toes are flexed. Place the leg back on the bed with the knee still bent and slowly increase hip flexion. This, in turn, increases the knee flexion, but the full range may be impossible. The longterm case with the tight Achilles tendon is a great problem (See illustration No. 3). If this type of patient starts to walk, a tendon lengthening operation may have to be done despite all one's efforts. It is not sufficient just to mobilse the limbs. Rotate the head; mobilise the shoulder-blades; rotate the trunk when the patient is on his side, or, if the legs are not too stiff, use one as a fulcrum for rotating the trunk when supine.

- Finally, remember in all cases:-

When tipping a patient for chest drainage and someone else has to be attended to, pull back the curtains so that the patient is under constant surveilance. No head-injured patient should be left alone behind curtains, as he may obstruct his airway or have a seizure without anybody being at hand. It is important that the fit can be seen by any staff there, and that its features be noted: whether occurring just in the face, or whether the arm and leg are also involved, and the exact time it lasts.
If one witnesses a fit, it should always be reported to the sister immediately.

2. Replace cotsides on the bed. A head-injured patient is sometimes confused and very restless and may fall out of bed repeatedly.

3. It is not always possible to exactly locate the brain lesion, and with some injuries the patient is able to take in what is being said around him even though he is quite unable to indicate this. Therefore, one should be very careful of what is said. Any despondent statement can be left unsaid until later.

4. The unconscious patient leads a very lonely life, so talk to him. By so doing, one stimulates his mental activity and that is a very important part of the total head injury treatment, and one cannot begin too early. Find out through a relative what the patient's home language is, because even if he could speak several languages previously, he will respond best at first to his native tongue. In certain parts of the world, this can involve the physiotherapist in considerable linguistic difficulties, but it is always worth the attempt!

\section{ACKNOWLEDGEMENTS}

$I$ would like to thank Professor J. C. de Villiers, Chief Consultant, Neuro-Surgical Unit, Groote Schuur Hospital, very much for his help in preparing this article, and for the lend of his photographs. In addition, thanks go to Miss Hebler for the typing of this article. 